\title{
Physical properties and biocompatibility of an injectable calcium-silicate-based root canal sealer: in vitro and in vivo study
}

\author{
Eun-Su Lim ${ }^{1,2}$, Young-Bae Park', Young-Sun Kwon ${ }^{1}$, Won-Jun Shon ${ }^{3 *}, K_{\text {wang-Won Lee }}^{1,2}$ and Kyung-San Min ${ }^{1,2^{*}}$
}

\begin{abstract}
Background: The aim of this study was to investigate the physical properties and biological effects of an experimentally developed injectable premixed calcium-silicate root canal sealer (Endoseal) in comparison with mineral trioxide aggregate (MTA) and a resin-based sealer (AHplus).

Methods: The $\mathrm{pH}$, solubility, dimensional change, flow, and radiopacity of the materials were evaluated. Biocompatibility was evaluated on the basis of cell morphology and a viability test using MC3T3-E1 cells. For evaluate inflammatory reaction, the tested sealers were implanted into dorsal subcutaneous connective tissue of Sprague Dawley rats. After 7 days, the implants with the surrounding tissue were retrieved, and histological evaluation was performed.
\end{abstract}

Results: Endoseal showed high alkalinity similar to that of MTA. The solubility of the tested materials was similar. The dimensional change and flow of Endoseal was significantly higher than that of other materials $(P<0.05)$. The radiopacity of Endoseal was lower than that of AHplus $(P<0.05)$. The biocompatibility was similar to those of MTA. Inflammatory reaction of Endoseal was similar with that of MTA, but lower than that of AHplus $(P<0.05)$.

Conclusions: The present study indicates that Endoseal has favorable physical properties and biocompatibility. Therefore, we suggest that Endoseal has the potential to be used as a predictable root canal sealer.

Keywords: Injectable, Calcium silicate, Root canal sealer, Physical, Biological

\section{Background}

Endodontic sealers are used for the obturation of root canal systems in order to achieve a fluid-tight seal between the dentinal wall and core filling material throughout the entire canal [1]. A root canal sealer must demonstrate appropriate physicochemical and biological properties. Grossmann stated that an ideal root canal sealer should possess excellent sealing ability, dimensional stability, a slow setting time, insolubility, and biocompatibility [2]. There are many types of root canal sealers available in the endodontic market; resin-based

\footnotetext{
* Correspondence: endoson@snu.ac.kr; endomin@gmail.com

${ }^{3}$ Department of Conservative Dentistry, Dental Research Institute and School of Dentistry, Seoul National University, 101 Daehak-ro, 03080 Seoul, Korea

'Department of Conservative Dentistry, School of Dentistry and Institute of Oral Bioscience, Chonbuk National University, 567 Baekje-daero, Jeonju-si 54896 , Korea

Full list of author information is available at the end of the article
}

sealers, zinc oxide-eugenol sealers, calcium hydroxidecontaining sealers, glass ionomer-based sealers, and mineral trioxide aggregate (MTA)-based calcium-silicate sealers. All of the currently used sealer systems consist of a powder/liquid or base/catalyst, and the two components should be mixed at chairside and then applied to the root canal system. Recently, an injectable calciumsilicate-based root canal sealer (Endoseal; Maruchi, Wonju, Korea) that is preserved in an air-tight syringe and applied in the root canal by injection was developed (Fig. 1a). Interestingly, Endoseal sets slowly by itself without any mixing when exposed to air by absorbing the ambient moisture.

According to the manufacturer, this calcium-silicate cement is considered an MTA-derived material because it contains similar chemical elements as MTA. Therefore, it is expected to have favorable physical and 

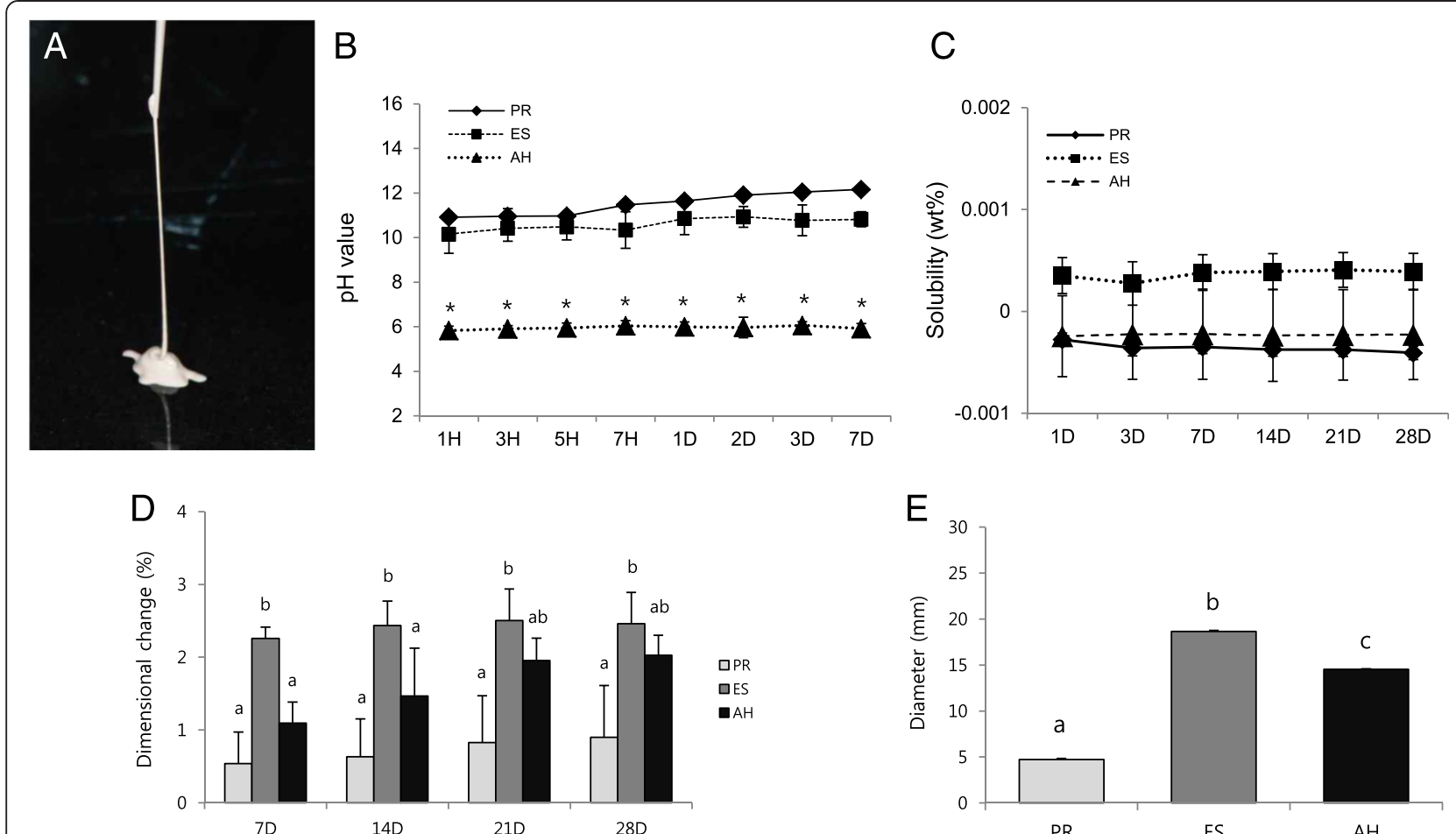

Fig. 1 Physicochemical properties of the tested materials. a The injectable calcium-silicate-based root canal sealer used in this study. $\mathbf{b}$ The changes in $\mathrm{pH}$ value during the experimental period. Groups identified by the same symbols were not significantly different in the same gene group $(P>0.05)$. Solubility $(\mathbf{c})$, dimensional change $(\mathbf{d})$, and e flow of the tested materials. Different letters/symbols represent significant differences between the different endodontic sealers $(P<0.05)$. PR; ProRoot, ES; Endoseal, AH; AHplus

biological effects like those of various MTA-derived materials demonstrated in previous studies [3-5]. Furthermore, many studies showed that MTA-derived root canal sealers have higher biocompatibility compared to resin-based sealers [6-9]. However, to our knowledge, there is little information regarding the self-setting calcium-silicate-based root canal sealer. Therefore, the aim of this study was to investigate the physical properties and biocompatibility of this root canal sealer in comparison with MTA (ProRoot; Dentsply, Tulsa, OK, USA) and a resin-based sealer (AHplus; DentsplyDe Trey, Konstanz, Germany).

\section{Methods}

\section{Measurement of $\mathrm{pH}$}

The $\mathrm{pH}$ was measured according to the criteria used in a previously published study [10]. Specimens (1-mm thickness and 5-mm diameter) of the tested materials were prepared and allowed to set for 1 day $(n=3)$. After setting, one tablet was added to $10 \mathrm{~mL}$ of deionized water. Then, the $\mathrm{pH}$ value was measured using a $\mathrm{pH}$ meter (Orion 3 Star; Thermo Scientific, Singapore). The apparatus was previously calibrated with $\mathrm{pH} 7.0$ and 4.0 solutions.

\section{Evaluation of solubility}

The solubility was measured by using the method recommended by ISO 6876/2012. Samples of each material were placed in a paraffin wax mold $1.5 \mathrm{~mm}$ thick and $20 \mathrm{~mm}$ in diameter $(n=3)$. Each sample was weighed using an analytical balance, and the weight was recorded as $W_{1}$. The samples were then immersed in tubes containing $10 \mathrm{~mL}$ of distilled water. Samples were removed at 1, 3, 7, and 14 days, dried with absorbent paper, and placed in a desiccator. The samples were dried to a constant weight $( \pm 0.001 \mathrm{~g})$, which was recorded as $\mathrm{W}_{2}$. The solubility $(\mathrm{S})$ was calculated using the following formula: $\mathrm{S}=\left(\mathrm{W}_{1}-\mathrm{W}_{2}\right) / \mathrm{W}_{1} \times 100$.

\section{Dimensional change}

The dimensional change was measured by using the method recommended by ISO $6876 / 2012$. Each material was placed into a cylindrical silicon mold with an internal diameter of $6 \mathrm{~mm}$ and a height of $12 \mathrm{~mm}$ $(n=5)$. After setting, we measured the distance between the flat ends (M1) to an accuracy of $10 \mu \mathrm{m}$ by using a digital caliper (Absolute Digimatic, Mitutoyo, Kawasaki, Japan). The materials were then stored in distilled water at $37 \pm 1{ }^{\circ} \mathrm{C}$. After 7,14 , and 21 days, the distance $\left(\mathrm{M}_{2}\right)$ was re-measured to an accuracy of 
$10 \mu \mathrm{m}$. The test was carried out three times, and the mean change in length was recorded as the dimensional change (D) using the following formula: $\mathrm{D}=\left(\mathrm{M}_{2}-\mathrm{M}_{1}\right) / \mathrm{M}_{1} \times 100$.

\section{Flow test}

The flow was tested by using the method recommended by ISO $6876 / 2012$. A total of $50 \mathrm{mg}$ of sealer was placed onto a glass plate $(n=3)$. After $180 \mathrm{~s}$, another glass plate was applied centrally on top of the material, to make a total mass on the plate of $120 \mathrm{~g}$. Ten minutes after the application, the load was removed, and the average of the major and minor diameters of the compressed discs was measured using a digital caliper. The mean of three measurements for each sealer was taken as the flow of the material.

\section{Radiopacity}

The radiopacity was measured by using the method recommended by ISO 6876/2012. The specimens were placed on occlusal X-ray film (Kodak Insight, Rochester, NY, USA) along with an aluminum (99.5\% pure) step wedge with step heights ranging from 1 to $10 \mathrm{~mm}$ in increments of $1 \mathrm{~mm}(n=5)$. A Kodak-2200 X-ray machine (Kodak) operating at $70 \mathrm{kV}, 10 \mathrm{~mA}, 18$ pulses/s and with a focus-sensor distance of $30 \mathrm{~cm}$ was used. After the films were developed, they were transformed into digital images (Fig. 2a) at a resolution of 300 dpi using a scanner. Then, the radiographic images were analyzed using a densitometer (GS-800; Bio-Rad, Hercules, CA, USA). In brief, we created a calibration curve for the aluminum step wedge, then the optical density of each specimen was expressed in terms of the equivalent thickness of the wedge in accordance with the following formula: $y=a \ln x+b$ (y: optical density, $x$ : thickness of aluminum, ' $a$ ' and ' $b$ ': coefficients, ln: natural log value).

\section{Preparation of material extracts}

The tested material was placed into a paraffin wax mold (1-mm thickness and 5-mm diameter). After setting, the cement was removed from the mold and stored in $10 \mathrm{~mL}$ of minimal essential medium- $\alpha$ (MEM- $\alpha$; HyClone Laboratories, Logan, UT, USA) containing $10 \%$ fetal bovine serum (FBS; HyClone Laboratories) for 3 days.

\section{Cell viability test}

MC3T3-E1 cells were seeded in 24-well culture plates (SPL Life Sciences, Pocheon, Korea) at a density of $2 \times 10^{4}$ cells per well and pre-incubated in growth medium for $24 \mathrm{~h}(n=5)$. Then, the cells were treated with the prepared extracts for $1,3,7$, and 14 days. Cell viability was measured using the 3-(4,5-dimethylthiazol-2-yl)-2,5-diphenyltetrazolium bromide (MTT) assay. Briefly, $200 \mu \mathrm{L}$ of MTT solution $(0.5 \mathrm{mg} / \mathrm{ml}$ in
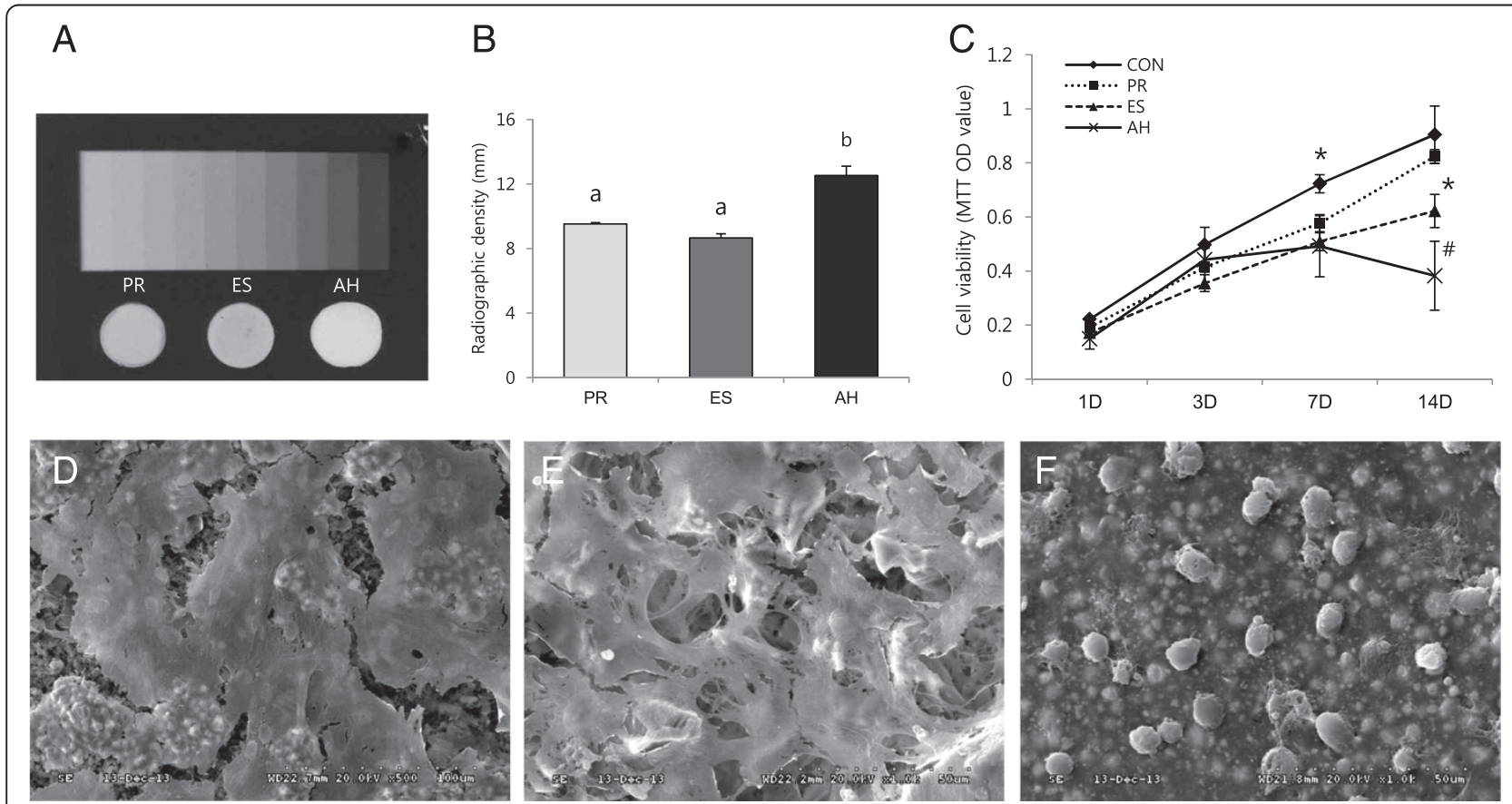

Fig. 2 Radiopacity and biocompatibility of the tested materials. a Radiograph showing the radiopacity of each material and its equivalence to that of the aluminum step wedge. b Relative radiographic density of each material in comparison with that of a 10-step aluminum step wedge. c Cell viability tested by the MTT assay. d-f SEM micrographs of MC3T3-E1 cells grown on ProRoot, Endoseal, and AHplus, respectively ( $\times 1000)$. Different letters/symbols represent significant differences between the different materials $(P<0.05)$. PR; ProRoot, EC; Endoseal, AH; AHplus 
PBS) (Amresco, Solon, OH, USA) was added to each well, and the wells were incubated for $2 \mathrm{~h}$. Subsequently, $200 \mu \mathrm{L}$ of dimethyl sulfoxide (DMSO; Amresco) was added to each well. Reduced MTT was then measured spectrophotometrically at $540 \mathrm{~nm}$ in a dual-beam microtiter plate reader (SPECTROstar Nano; BMG Labtech, Ortenberg, Germany).

\section{Cell morphological observations using SEM}

Under aseptic conditions, materials were condensed into $1 \times 5$ - $\mathrm{mm}$ round wax molds. The materials were allowed to set for $24 \mathrm{~h}$ in a humidified incubator at $37{ }^{\circ} \mathrm{C}$. Then, the disks were placed at the bottom of 24-well tissue culture plates (SPL Life Sciences). MC3T3-E1 cells were seeded at $1 \times 10^{5}$ cells per well on the prepared materials. After a 72-h incubation period, the dishes were fixed with $2.5 \%$ glutaraldehyde (Sigma-Aldrich, St. Louis, MO, USA) for $2 \mathrm{~h}$. Samples were then dehydrated in increasing concentrations of ethanol (70 \%, $80 \%, 90 \%, 95 \%$, and $100 \%)$ for $20 \mathrm{~min}$ at each concentration and immersed in n-butyl alcohol (Junsei Chemical Co., Tokyo, Japan) for $20 \mathrm{~min}$. SEM was performed using an SN-3000 system (Hitachi, Tokyo, Japan) operated at $10 \mathrm{kV}$.

\section{Histological evaluation of inflammatory reaction}

The inflammatory reactions of animal tissue to ProRoot, Endoseal, and AHplus were evaluated $(n=6)$. The sealers were inserted into sterile polyethylene tubes approximately $10 \mathrm{~mm}$ height and $3 \mathrm{~mm}$ in inner diameter. After setting, the materials were implanted in the Sprague Dawley rats' dorsal subcutaneous tissue. An empty tube was used as the negative control. In brief, the animals were anesthetized with $0.33 \mathrm{~mL} / 100 \mathrm{~g}$ xylazine hydrochloride (Rompun, Bayer, Leverkusen, Germany) and $0.2 \mathrm{~mL} / 100 \mathrm{~g}$ zolazepam (Zoletil 50; Virbac SA, Carros, France), followed by shaving of dorsal fur, disinfection, incision, and divulsion of the subcutaneous tissue to insert the testing materials. Each animal received 4 materials. The position in which each sealer was implanted was standardized. The incisions were closed using a 5-0 Vicryl suture material (Johnson \& Johnson, Lenneke Marelaan, Belgium).

After 7 days, the animals were euthanized by $\mathrm{CO}_{2}$ inhalation. An excisional biopsy of the implant area was performed with a safety margin of $1 \mathrm{~cm}$. The samples were fixed in $4 \%$ paraformaldehyde for $24 \mathrm{~h}$, and the materials were removed from the samples. Then, the samples were set in paraffin blocks, and processed for histologic analysis. Sections with a thickness of $5 \mu \mathrm{m}$ were stained with hematoxylin-eosin. Three representative sections were examined under a light microscope by a single-blinded, calibrated examiner. Quantitative evaluations of inflammatory cells (lymphocytes and polymorphonuclear leukocytes) were made in ten separate areas of sections at $\times 400$ magnifications. An average value for each material was obtained from the sum of cells counted in ten separate areas. Inflammatory reactions were scored and evaluated according to the criteria used in a previously published study with slight modification as follows [11]; 0, none or few inflammatory cells and no reaction; $1,<25$ cells and mild reaction; 2, between 25 and 125 cells and moderate reaction; $3, \geq 125$ cells and severe reaction. These experimental procedures were approved by the Institutional Animal Care and Use Committees (IACUC) of Chonbuk National University Hospital (Jeonju, Korea).

\section{Statistical analysis}

Statistical analysis was performed by one-way ANOVA followed by Tukey's test for physical properties, cell viability, and gene expression assay $(P=0.05)$. For histological evaluation, the data were evaluated using one-way nonparametric Kruskal-Wallis for a $5 \%$ significance level.

\section{Results}

Measurement of $\mathrm{pH}$, solubility, dimensional change, flow, and radiopacity

The $\mathrm{pH}$ values of ProRoot and Endoseal showed high alkalinity ( $\mathrm{pH}$ between 10 and 12), whereas AHplus showed mild acidity around pH 6 (Fig. 1b). The solubility values of the tested materials were similar throughout the experimental period $(P>0.05)$ (Fig. 1c). As shown in Fig. 1d, the dimensional change of Endoseal was significantly higher than that of the other materials at all experimental time points $(P<0.05)$. The flow of Endoseal was significantly higher than that of other materials $(P<0.05)$ (Fig. 1e). The radiopacity of AHplus was higher than those of ProRoot and Endoseal $(P<0.05)$. However, all the materials evaluated presented the minimum radiopacity required by the ISO standard (Fig. 2b).

\section{Biocompatibility}

To evaluate cell viability in the presence of the material extracts, an MTT assay was performed. As shown in Fig. 2c, ProRoot showed significantly higher cell viability compared to the other groups on 14 -day $(P<0.05)$. Further, the viability of Endoseal-treated cells was significantly higher than that of AHplus-treated cells on 14-day $(P<0.05)$. The cell growth and morphology on each material were evaluated by SEM. As shown in Fig. $2 \mathrm{~d}$ and e, well-spread and flattened cells were observed in contact with the surfaces of ProRoot and Endoseal. On the contrary, round but dead cells were observed on the surface of AHplus (Fig. 2f). Moreover, in histological evaluation, inflammatory scores of ProRoot and Endoseal group were significantly lower than that of AHplus group $(P<0.05)$ (Fig. 3). 


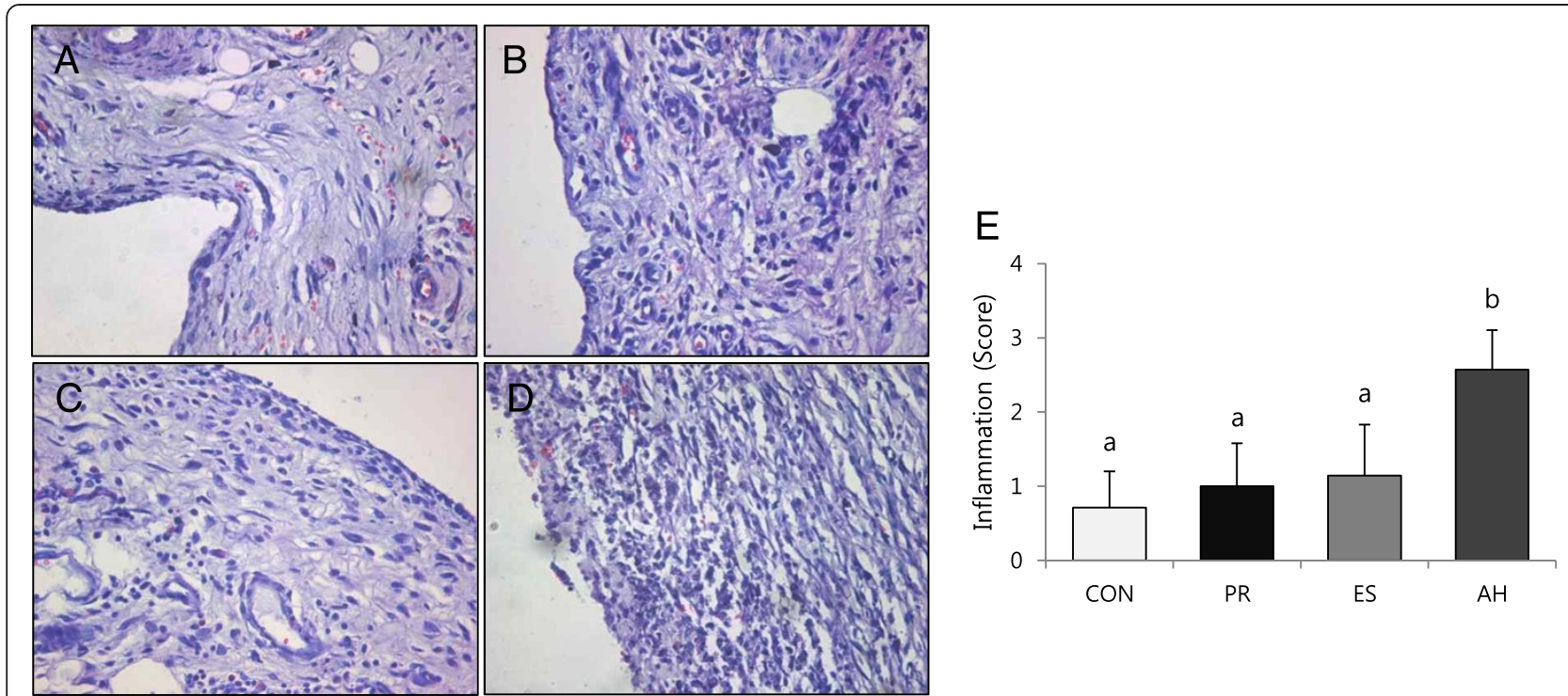

Fig. 3 Reaction of rat subcutaneous connective tissue to the tested sealers and the control group after 7 days ( $H$ \& E staining, $\times 100)$; a control, b ProRoot, c Endoseal, d AHplus. e Mean and standard deviation of histological scores. Different letters represent significant differences between the different materials $(P<0.05)$

\section{Discussion}

According to Grossman, an ideal root canal sealer should provide various physical properties [2]. Among them, we evaluated $\mathrm{pH}$, solubility, dimensional change, flow and radiopacity. In our study, Endoseal showed high alkalinity $(\mathrm{pH} 10-11)$ similar to that of ProRoot (Fig. 1b). The base material of Endoseal is calciumsilicate with a chemical composition very similar to that of MTA. It is generally believed that MTA and its derivatives dissolve into calcium hydroxide when coming into contact with soft tissue, which results in a high $\mathrm{pH}$ [12]. The high $\mathrm{pH}$ of root canal sealers may provide several biological advantages. First, high $\mathrm{pH}$ of the sealer can promote hard tissue formation such as apical obliteration with calcified tissue [13]. Second, high sealer alkalinity changes the environment in the dentin to a more alkaline $\mathrm{pH}$, possibly interfering with osteoclastic activity and promoting alkalinization in the adjacent tissues, which favors healing [14, 15]. Furthermore, there have been several studies demonstrated that calcium-hydroxide itself inhibited osteoclast activity by various molecular mechanisms [16-19]. Therefore, the high $\mathrm{pH}$ of Endoseal may exert an advantageous effect through the aforementioned mechanism compared to conventional resin-based sealers.

In the current study, water solubility of the tested sealers was evaluated because there is a strong link between sealer solubility and periapical reinfection [20]. In our study, the water solubility of Endoseal was the highest among the tested materials although there was no significant difference among the three experimental groups $(P>0.05)$ (Fig. 1c).
Dimensional change demonstrates the shrinkage or expansion of the material after setting. In this study, all the tested materials showed expansion. In previous reports, expansion was also verified for ProRoot and AHplus [21-23]. It is interesting to note that Endoseal expanded significantly more than the other tested materials $(P<0.05)$ (Fig. 1d). Slight expansion may contribute to superior sealing ability, but excessive expansion is undesirable when the material is employed as a root canal filling material as it may elicit cracks in the root [21]. Thus, further tests are required to ascertain if Endoseal effectively seals root canals without increasing the risk of development of cracks or root fracture.

Flow allows a sealer to penetrate into the irregularities and accessory canals of the root canal system [24]. In this study, Endoseal showed significantly higher flow values compared with AHplus $(P<0.05)$ (Fig. 1e). In this respect, Endoseal would have advantage in terms of penetrating into the ramifications and irregularities of root canal system than AHplus. The flow ability is generally influenced by the size of the sealer particles. According to the manufacture, Endoseal contains small particles of calcium-silicate cement to increase the flow. However, if the flow is excessive, the risk of sealer extrusion beyond apical foramen is increased, which could damage periodontal tissues or important anatomical structures such as inferior alveolar nerve or maxillary sinus [25]. Because Endoseal is injectable material which is susceptible to be extruded, clinicians should be careful not to try to fill whole root canal space with it. In this respect, further in vitro or in vivo study 
should be performed to conclude the adequate flow of Endoseal.

The addition of radiopaque agents to root canal filling materials should ideally enable their visualization and assessment on a radiograph without altering their chemical properties. According to the ISO standards, root canal sealing materials should be at least $3 \mathrm{~mm}$ in aluminum thickness. In the present study, the radiopacity of Endoseal was lower than that of AHplus $(P<0.05)$ (Fig. 2b). However, Endoseal showed much higher radiopacity (over $8 \mathrm{~mm} / \mathrm{Al}$ ) than that required by the ISO standards, similar to ProRoot and AHplus.

Endodontic sealers are often placed in close contact with periapical tissues. Thus, we investigated the biocompatibility of Endoseal in comparison with ProRoot and AHplus. As shown in Fig. 2c, the cell viability was also higher in cells treated with an extract of Endoseal than in cells treated with AHplus on 14-day $(P<0.05)$. However, the cell viability was significantly lower than that of ProRoot. Similarly, SEM observations in this study showed that the cells were attached and had proliferated on the surface of Endoseal and ProRoot, whereas dead cells were found on the surface of AHplus (Fig. 2d-f). These findings indicate that calcium-silicatebased Endoseal has higher biocompatibility compared to epoxy resin-based AHplus and permits adhesion and proliferation of cells.

We also investigated the tissue response to verify whether the materials induce inflammatory reaction in vivo. Several in vivo studies have shown that most of root canal sealers might induce inflammatory reactions when they contact with connective tissues intimately [26-29]. However, in this study, ProRoot and Endoseal did not show severe inflammatory reaction compared to control group. Calcium-silicate cements such as MTA is believed to induce less inflammation tissue reaction compared to other root canal filling materials [30-34]. In this respect, Endoseal, calcium-silicate cement, might show favorable tissue response comparable to ProRoot although it may contain various chemical ingredients.

We requested the chemical composition of Endoseal from the manufacturer in order to understand in detail the physical properties and biological effects determined in our experiments. According to the manufacturer, Endoseal contains various constituents including hydroxypropyl methylcellulose (HPMC), N-methyl-2pyrrolidone (NMP), bentonite, bismuth oxide $\left(\mathrm{Bi}_{2} \mathrm{O}_{3}\right)$, and zirconium oxide $\left(\mathrm{ZrO}_{2}\right)$. HPMC is a non-toxic thickening agent and can react vigorously with oxidizing agents. Use of viscosity agents is suggested for sealer development in order to penetrate into the complex root canal space. NMP is used as a solvent for various chemical agents but has been identified as a toxicant [35]. In this study, Endoseal showed significantly lower cell viability compared to ProRoot $(P<0.05)$ (Fig. 2d), and the presence of NMP in Endoseal might have affected this result. Bentonite is a useful adsorbent of ions in solution as well as fats and oils. It is the main active ingredient of fuller's earth, probably one of the earliest industrial cleaning agents. It is mainly recommended as an ingredient of preparations for dermatologic ointments because its colloidal nature confers detergent properties [36]. Therefore, bentonite is added to the formula to absorb moisture and contamination from the mixture. $\mathrm{Bi}_{2} \mathrm{O}_{3}$ and $\mathrm{ZrO}_{2}$ are components in Endoseal that act as radiopacifiers and are widely used in MTA and other endodontic materials [37-39].

\section{Conclusions}

Collectively, the present study indicates that Endoseal has comparable physical properties to MTA, a biocompatible root-end filling material. In addition, Endoseal had favorable biocompatibility/odontogenicity compared to AHplus, a widely used resin-based sealer. Furthermore, this injection-type, self-setting root canal sealer has a clinical advantage in terms of dentist-friendly application. Therefore, within the limitations of this study, we suggest that Endoseal has the potential to be used as a predictable root canal sealer.

\section{Competing interests}

The authors declare that they have no competing interests.

\section{Authors' contributions}

Min KS, Shon WJ and Lee KW contributed to planning and designing the study, in the data analysis and submission of the manuscript. Lim ES performed most of the laboratory work. Park YB and Kwon YS performed the animal study. All authors have read and approved the final manuscript.

\section{Acknowledgments}

This research was financially supported by the Ministry of Trade, Industry \& Energy (MOTIE), Korea Institute for Advancement of Technology (KIAT), and Gangwon Institute for Regional Program Evaluation (GWIRPE) through the Leading Industry Development for Economic Region.

Shon WJ and Min KS contributed to this work as corresponding authors.

\section{Author details}

${ }^{1}$ Department of Conservative Dentistry, School of Dentistry and Institute of Oral Bioscience, Chonbuk National University, 567 Baekje-daero, Jeonju-si 54896, Korea. ${ }^{2}$ Research Institute of Clinical Medicine of Chonbuk National University-Biomedical Research Institute of Chonbuk National University Hospital, 20 Geonji-ro, 54907 Jeonju-si, Korea. ${ }^{3}$ Department of Conservative Dentistry, Dental Research Institute and School of Dentistry, Seoul National University, 101 Daehak-ro, 03080 Seoul, Korea.

Received: 28 April 2015 Accepted: 8 October 2015

Published online: 21 October 2015

References

1. Branstetter J, von Fraunhofer JA. The physical properties and sealing action of endodontic sealer cements: a review of the literature. J Endod. 1982;8:312-6.

2. Grossman LI. Endodontic Practice. 10th ed. Philadelphia: Henry Kimpton Publishers; 1981. p. 297.

3. Viola NV, Guerreiro-Tanomaru JM, da Silva GF, Sasso-Cerri E, Tanomaru-Filho M, Cerri PS. Biocompatibility of an experimental MTA sealer implanted in the rat 
subcutaneous: quantitative and immunohistochemical evaluation. J Biomed Mater Res B Appl Biomater. 2012;100:1773-81.

4. Lee SJ, Chung J, Na HS, Park EJ, Jeon HJ, Kim HC. Characteristics of novel root-end filling material using epoxy resin and Portland cement. Clin Oral Investig. 2013;17:1009-15.

5. Willershausen I, Wolf T, Kasaj A, Weyer V, Willershausen B, Marroguin BB. Influence of a bioceramic root end material and mineral trioxide aggregates on fibroblasts and osteoblasts. Arch Oral Biol. 2013:58:1232-7.

6. Zhang W, Li Z, Peng B. Ex vivo cytotoxicity of a new calcium silicate-based canal filling material. Int Endod J. 2010;43:769-74.

7. Gandolfi MG, Perut F, Ciapetti G, Mongiorgi R, Prati C. New Portland cement-based materials for endodontics mixed with articaine solution: a study of cellular response. J Endod. 2008;34:39-44.

8. Bin CV, Valera MC, Camargo SE, Rabelo SB, Silva GO, Balducci I, et al. Cytotoxicity and genotoxcity of root canal sealers based on mineral trioxide aggregate. J Endod. 2012:38:495-500.

9. Zoufan K, Jiang J, Komabayashi T, Wang YH, Safavi KE, Zhu Q. Cytotoxicity evaluation of Gutta Flow and Endo Sequence BC sealers. Oral Surg Oral Med Oral Pathol Oral Radiol Endod. 2011;112:657-61.

10. Lee JB, Park SJ, Kim HH, Kwon YS, Lee KW, Min KS. Physical properties and biological/odontogenic effects of an experimentally developed fast-setting a-tricalcium phosphate-based pulp capping material. BMC Oral Health 2014;14:87.

11. Yaltirik M, Ozbas $H$, Bilgic $B$, Issever $H$. Reactions of connective tissue to mineral trioxide aggregate and amalgam. J Endod. 2004;30:95-9.

12. Fridland $M$, Rosado R. Mineral trioxide aggregate (MTA) solubility and porosity with different water-to-powder ration. J Endod. 2003;29:814-7.

13. Tagger M, Tagger E. Periapical reactions to calcium hydroxide-containing sealers and AH 26 in monkeys. Endod Dent Traumatol. 1989;5:139-46.

14. Tronstad L, Andreasen JO, Hasselgren G, Kristerson L, Riis I. pH changes in dental tissues after root canal filling with calcium hydroxide. J Endod. 1981;7:17-21.

15. Gomes-Filho JE, Watanabe S, Lodi CS, Cintra LT, Nery MJ, Filho JA, et al. Rat tissue reaction to MTA FILLAPEX ${ }^{\circledR}$. Dent Traumatol. 2012;28:452-6.

16. Jiang J, Zuo J, Chen SH, Holliday LS. Calcium hydroxide reduces lipopolysaccharide-stimulated osteoclast formation. Oral Surg Oral Med Oral Pathol Oral Radiol Endod. 2003;95:348-54

17. Rodrigues C, Costa-Rodrigues J, Capelas JA, Fernandes MH. Long-term doseand time-dependent effects of endodontic sealers in human in vitro osteoclastogenesis. J Endod. 2013;39:833-8.

18. Guo J, Yang D, Okamura H, Termachi J, Ochiai K, Qiu L, et al. Calcium hydroxide suppresses Porphyromonas endodontalis lipopolysaccharide-induced bone destruction. J Dent Res. 2014;93:508-13.

19. Han B, Wang X, Liu J, Liang F, Qu X, Yang Z, et al. Influence of calcium hydroxide-loaded microcapsules on osteoprotegerin and receptor activator of nuclear factor kappa B ligand activity. J Endod. 2014;40:1977-82.

20. Donnelly A, Sword J, Nishitani Y, Yoshiyama M, Agee K, Tay FR, et al. Water sorption and solubility of methacrylate resin-based root canal sealers. J Endod. 2007:33:990-4.

21. Islam I, Chng HK, Yap AU. Comparison of the physical and mechanical properties of MTA and Portland cement. J Endod. 2006:32:193-7.

22. Resende LM, Rached-Junior FJ, Versiani MA, Souza-Gabriel AE, Miranda CE, Silva-Sousa YT, et al. A comparative study of physicochemical properties of AH Plus, Epiphany, and Epiphany SE root canal sealers. Int Endod J. 2009:42:785-93.

23. Versiani MA, Carvalho-Junior JR, Padilha MI, Lacey S, Pascon EA, Sousa-Neto MD. A comparative study of physicochemical properties of AH Plus and Epiphany root canal sealants. Int Endod J. 2006;39:464-71.

24. Silva EJ, Rosa TP, Herrera DR, Jacinto RC, Gomes BP, Zaia AA. Evaluation of cytotoxicity and physicochemical properties of calcium silicate-based endodontic sealer MTA Fillapex. J Endod. 2013;39:274-7.

25. Almeida JF, Gomes BP, Ferraz CC, Souza-Filho FJ, Zaia AA. Filling of artificia lateral canals and microleakage and fiow of five endodontic sealers. Int Endod J. 2007:40:692-9.

26. Kaplan AE, Ormaechea MF, Picca M, Canzobre MC, Ubios AM. Rheological properties and biocompatibility of endodontic sealers. Int Endod J. 2003;6:527-32

27. Valera MC, Leonardo MR, Consolaro A, Matuda Fda S. Biological compatibility of some types of endodontic calcium hydroxide and glass ionomer cements. J Appl Oral Sci. 2004;12:294-300.
28. Zmener $\mathrm{O}$, Banegas $\mathrm{G}$, Pameijer $\mathrm{CH}$. Bone tissue response to a methacrylate-based endodontic sealer: a histological and histometric study. J Endod. 2005;31:457-9.

29. Scarparo RK, Grecca FS, Fachin EV. Analysis of tissue reactions to methacrylate resin-based, epoxy resin-based, and zinc oxide-eugenol endodontic sealers. J Endod. 2009;35:229-32

30. Torabinejad M, Ford TR, Abedi HR, Kariyawasam SP, Tang HM. Tissue reaction to implanted root-end filling materials in the tibia and mandible of guinea pigs. J Endod. 1998;24:468-71.

31. Economides N, Pantelidou O, Kokkas A, Tziafas D. Short-term periradicular tissue response to mineral trioxide aggregate (mTA) as root-end filling material. Int Endod J. 2003;36:44-8.

32. Saidon J, He J, Zhu Q, Safavi K, Spångberg LS. Cell and tissue reactions to mineral trioxide aggregate and Portland cement. Oral Surg Oral Med Oral Pathol Oral Radiol Endod. 2003;95:483-99.

33. Modaresi J, Yavari SA, Dianat SO, Shahrabi S. A comparison of tissue reaction to MTA and an experimental root-end restorative material in rat. Aust Endod J. 2005;31:69-72.

34. Bernabé PF, Gomes-Filho JE, Rocha WC, Nery MJ, Otoboni-Filho JA Dezan-Júnior E. Histological evaluation of MTA as a root-end filling material. Int Endod J. 2007;40:758-65.

35. Leira HL, Tiltnes A, Svenden $K$, Vetlesen L. Irritant cutanious reactions to N-methyl-2-pyrolidone (NMP). Contact Dermatitis. 1992;27:148-50.

36. Hollander L, Mcclenahan WS. Clinical investigation of bentonite-petrolatun ointments and ointments bases. J Invest Dermatol. 1948;11:127-36.

37. Min KS, Chang HS, Bae JM, Park SH, Hong CU, Kim EC. The induction of heme oxygenase-1 modulates bismuth oxide induced cytotoxicity in human dental pulp cells. J Endod. 2007:33:1342-6.

38. Kim EC, Lee BC, Chang HS, Lee W, Hong CU, Min KS. Evaluation of the radiopacity and cytotoxicity of Portland cements containing bismuth oxide. Oral Surg Oral Med Oral Pathol Oral Radiol Endod. 2008;105:e54-7.

39. Cutajar A, Mallia B, Abela S, Camilleri J. Replacement of radiopacifier in mineral trioxide aggregate; characterization and determination of physical properties. Dent Mater. 2011;27:879-91.

\section{Submit your next manuscript to BioMed Central and take full advantage of:}

- Convenient online submission

- Thorough peer review

- No space constraints or color figure charges

- Immediate publication on acceptance

- Inclusion in PubMed, CAS, Scopus and Google Scholar

- Research which is freely available for redistribution 